\title{
ВОЗРАСТНЫЕ И ПОЛОВЫЕ ОСОБЕННОСТИ ЛИЧНОСТНЫХ ПРЕДИКТОРОВ АНТИСОЦИАЛЬНОЙ КРЕАТИВНОСТИ
}

\section{Н.В. МЕШКОВА О.Г. КРАВЦОВ , М.Н. БОЧКОВА, И.А. МЕШКОВ}

\begin{abstract}
${ }^{a}$ Московский государственный психолого-педагогический университет, 127051, Россия, Москва, ул. Сретенка, д. 29

${ }^{b}$ Федеральное государственное бюджетное научное учреждение «Научный центр психического здоровья», 115522, Россия, Москва, Каширское шоссе, д. 34

' УНК ПСД Московского университета МВД России им. В.Я. Кикотя
\end{abstract}

\begin{abstract}
Резюме
Антисоциальная (malevolent) креативность (АК) проявляется в реализации чужих или собственных оригинальных идей, наносящих вред другим людям. Анализ исследований показывает, что существуют возрастные и гендерные особенности в антисоциальной креативности. В статье приводятся результаты исследования предикторов АК с учетом возраста и пола респондентов. Состав выборки $(\mathrm{N}=293)$ : мужчины $(\mathrm{N}=192)$; кадеты $(\mathrm{N}=97)$, курсанты $(\mathrm{N}=150)$ и студенты $(\mathrm{N}=46$, все женщины). Использовалась батарея опросников: Поведенческие особенности антисоциальной креативности (в адаптации Н.В. Мешковой и др.), агрессии Басса-Перри (в адаптации С.Н. Ениколопова, Н.П. Цибульского), сокращенный вариант NEO-FFI опросника NEO PI-R П. Коста и Р. Макраэ (в адаптации В.Е. Орла, И.Г. Сенгина), «ЭмИн» (Д.В. Люсин), МАК-4 (в адаптации В.В. Знакова). Мы выявили качественные возрастные и половые особенности личностных предикторов антисоциальной креативности: у мужчин - это враждебность, у женщин - агрессия. Согласно результатам регрессионного анализа, специфика подростковой антисоциальной креативности состоит в том, что в число отрицательных предикторов входят черты Большой пятерки «Согласие» и «Добросовестность», связанные с девиантным поведением, чего не наблюдалось у взрослых респондентов. Полученные результаты могут быть использованы для разработки программ по профилактике девиантного поведения у подростков.
\end{abstract}

Ключевые слова: антисоциальная креативность, кадеты, курсанты, черты «Большой пятерки», враждебность, агрессия.

Исследование выполнено при финансовой поддержке Российского фонда фундаментальных исследований в рамках научного проекта № 19-013-00240-А. 


\section{Введение}

Феномен антисоциальной (malevolent) креативности (АК) проявляется в поведении, наносящем намеренный вред другим людям в результате решения нелегитимной задачи деструктивными способами (Мешкова, Ениколопов, 2018). При адаптации опросника «The malevolent creativity behavior scale» (Hao et al., 2016) (в российской версии - «Поведенческие особенности антисоциальной креативности» (ПОАК)) в 2016-2018 гг. на российской выборке были получены данные, согласно которым можно предполагать, что существуют, во-первых, возрастные и половые особенности в предикторах антисоциальной креативности, во-вторых, поведенческие и когнитивные предикторы АК, так как опросник включает вопросы, касающиеся либо идей и мыслей о нанесении вреда оригинальными способами, либо об их непосредственном воплощении в поведении (Мешкова и др., 2018в). Наличие креативного потенциала в данном случае может быть не обязательным условием, и тогда на первый план выходят психологические характеристики, при которых индивиды реализуют в поведении, наносящем вред, чужие оригинальные идеи. В повседневной жизни таким поведением являются ложь, нанесение вреда другим оригинальными способами при сведении счетов или мести, злословие (Нао et al., 2016), которое может проявиться в буллинге, кибер-преступлениях, коррупции и мошенничестве. На настоящий момент проблема профилактики коррупционного поведения в правоохранительной системе является одной из актуальных и острых, поэтому чрезвычайно важным представляется исследование антисоциальной креативности у кадетов и курсантов как будущих полицейских, чье предназначение состоит в том, чтобы предотвращать такое поведение.

Целью настоящей статьи является выявление возрастных и половых особенностей личностных предикторов антисоциальной креативности. На разных возрастных выборках было показано, что предикторами АК являются: 1) у студентов (из них бо́льшая часть женщины) - агрессия как интегральный показатель (Ibid.); 2) у осужденных за различные правонарушения - враждебность (когнитивный компонент агрессии) и низкая выраженность ценностей социального фокуса (Мешкова, 2018; Мешкова и др., 2018а), а также низкий уровень понимания собственных эмоций в структуре эмоционального интеллекта (Бочкова, 2020); 3) в выборке кадетов - враждебность, макиавеллизм, низкие нейротизм и черта «Большой пятерки» «Согласие» (Мешкова и др., 2018б); компоненты агрессии, слабо выраженные черты «Большой пятерки» («Согласие» и «Добросовестность»), макиавеллизм вносят вклад (в разных сочетаниях) как предикторы в шкалы ПОАК («Нанесение вреда», «Ложь» и «Злые шутки») (Бочкова, Мешкова, 2019); 4)у сотрудников полиции с неюридическим образованием - враждебность и агрессия (Мешкова и др., 2018б). Приведенные результаты позволяют предположить, что в число личностных предикторов антисоциальной креативности у подростков будут входить черты «Большой пятерки», в то время как у взрослых респондентов такая закономерность будет отсутствовать (первая гипотеза). Принимая во 
внимание то, что бо́льшую часть испытуемых в проведенных исследованиях составляли представители мужского пола, мы предположили, что личностным предиктором антисоциальной креативности у мужчин является враждебность (вторая гипотеза).

\section{Методы}

\section{Въцборка}

В качестве испытуемых $(\mathrm{N}=293)$ выступили студенты психологического вуза г. Москвы $(\mathrm{N}=46$, из них все женщины), курсанты $(\mathrm{N}=150$, из них мужчины -120$)$ и кадеты $(\mathrm{N}=97$, из них мужчины - 72).

\section{Методики}

Использовались следующие опросники: опросник агрессии Басса-Перри (Ениколопов, Цибульский, 2007), измеряющий компоненты агрессии, сокращенный вариант NEO-FFI опросника NEO PI-R П. Коста и Р. Макраэ (Орел, Сенгин, 2004), «ЭмИн» (Люсин, 2009), МАК-4 (Знаков, 2000). Также использовался адаптированный на российской выборке опросник «The malevolent creativity behavior scale» (Наo et al., 2016), состоящий из трех шкал: «Нанесение вреда», «Ложь» и «Злые шутки». Опросник показал хорошие результаты конструктной валидности и надежности в измерении антисоциально направленной креативности (Мешкова и др., 2018в). Авторы оригинальной версии опросника взяли за основу наблюдаемое в повседневной жизни поведение, в котором может воплощаться креативная мысль для нанесения вреда: месть за нанесенную обиду, обман, подшучивание, злой розыгрыш (Наo et al., 2016). Опросник включает 12 вопросов, баллы на которые подсчитывались согласно процедуре, описанной в материалах по адаптации (Мешкова и др., 2018в).

Статистическая обработка проводилась с помощью SPSS Statistics 23.0.

\section{Результаты исследования}

Различия в АК, агрессии, чертах «Большой пятерки», компонентах эмоционального интеллекта между выборками женского и мужского пола проверялись по критерию Манна-Уитни. Было установлено, что выборки кадетов и курсантов женского и мужского пола различаются уровнем АК (значимость различий между женскими выборками $p<0.05$, между мужскими $p<0.01$ ), агрессией (значимость различий между женскими выборками и между мужскими выборками в обоих случаях $p<0.01$ ), враждебностью (значимость различий между женскими выборками и между мужскими выборками в обоих случаях $p<0.01)$. В свою очередь, курсанты отличаются от кадетов большей выраженностью понимания собственных эмоций и чертой «Большой пятерки» - «Согласие» (выявлено у испытуемых обоего пола, значимость различий 
в обоих случаях $p<0.01)$ и «Добросовестностью» (выявлено только у представителей мужского пола, значимость различий $p<0.01)$ (см. таблицу 1$)$.

Что касается различий в выборках по полу, то здесь мы получили следующие данные в непараметрических сравнениях по критерию Манна-Уитни (у курсантов женского и мужского пола) и t-критерию (у кадетов женского и мужского пола): у курсантов-мужчин выше уровень агрессии и макиавеллизма и менее выражена черта «Согласие» по сравнению с курсантами женского пола (уровень значимости $p<0.01)$. У кадетов мужского пола выше уровень агрессии и ниже уровень враждебности по сравнению с кадетами женского пола (значимость $p<0.05)$ (см. таблицу 2).

Таблица 1

Различия показателей по критерию Манна-Уитни в выборках по возрастам

\begin{tabular}{|l|c|c|c|c|}
\hline \multirow{2}{*}{\multicolumn{1}{|c|}{ Параметры }} & \multicolumn{2}{|c|}{ Средний ранг } & \multicolumn{2}{c|}{ Средний ранг } \\
\cline { 2 - 5 } & $\begin{array}{c}\text { Курсанты- } \\
\text { женщины } \\
(\mathrm{N}=30)\end{array}$ & $\begin{array}{c}\text { Кадеты- } \\
\text { женщины } \\
(\mathrm{N}=25)\end{array}$ & $\begin{array}{c}\text { Курсанты- } \\
\text { мужчины } \\
(\mathrm{N}=119)\end{array}$ & $\begin{array}{c}\text { Кадеты- } \\
\text { мужчины } \\
(\mathrm{N}=72)\end{array}$ \\
\hline Антисоциальная креативность & 23.38 & $33.54^{*}$ & 83.93 & $115.94^{* *}$ \\
\hline Агрессия & 22.48 & $34.62^{* *}$ & 83.81 & $115.10^{* *}$ \\
\hline Гнев & - & - & 86.24 & $111.01^{* *}$ \\
\hline Враждебность & 19.43 & $38.28^{* *}$ & 79.29 & $122.68^{* *}$ \\
\hline Согласие & $33.22^{* *}$ & 21.74 & $104.35^{* *}$ & 80.67 \\
\hline Добросовестность & - & - & $106.54^{* *}$ & 77.00 \\
\hline Понимание своих эмоций & $30.27^{* *}$ & 16.68 & $77.84^{* *}$ & 52.79 \\
\hline
\end{tabular}

${ }^{*} p<0.05,{ }^{* *} p<0.01$.

Таблица 2

Различия показателей в выборках по полу

\begin{tabular}{|l|c|c|c|c|}
\hline \multirow{3}{*}{ Параметры } & \multicolumn{2}{|c|}{$\begin{array}{c}\text { Средний ранг и уровень } \\
\text { значимости по критерию } \\
\text { Манна-Уитни }\end{array}$} & \multicolumn{2}{|c|}{$\begin{array}{c}\text { Средние и значимость } \\
\text { по t-критерию }\end{array}$} \\
\cline { 2 - 5 } & $\begin{array}{c}\text { Курсанты- } \\
\text { мужчины } \\
(\mathrm{N}=119)\end{array}$ & $\begin{array}{c}\text { Курсанты- } \\
\text { женщины } \\
(\mathrm{N}=30)\end{array}$ & $\begin{array}{c}\text { Кадеты- } \\
\text { мужчины } \\
(\mathrm{N}=72)\end{array}$ & $\begin{array}{c}\text { Кадеты- } \\
\text { женщины } \\
(\mathrm{N}=25)\end{array}$ \\
\hline Агрессия & $80.94^{* *}$ & 51.43 & $52.03^{*}$ & 38.48 \\
\hline Враждебность & - & - & 44.7 & $59.3^{*}$ \\
\hline Согласие & 69.78 & $95.72^{* *}$ & - & - \\
\hline Макиавеллизм & $79.47^{* *}$ & 52.98 & - & - \\
\hline
\end{tabular}

${ }^{*} p<0.05,{ }^{* *} p<0.01$. 
Были выявлены следующие значимые корреляции по Спирмену антисоциальной креативности с показателями агрессии, чертами «Большой пятерки», макиавеллизмом и компонентами эмоционального интеллекта: у кадетов мужского пола - положительные корреляции с гневом и враждебностью, отрицательные - с «Согласием» и «Добросовестностью» (уровень значимости корреляций во всех случаях $p<0.01)$; у кадетов женского пола - положительные с агрессией, враждебностью, макиавеллизмом, отрицательные - c «Согласием» и «Добросовестностью» (уровень значимости корреляций $p<0.01$; $p<0.01 ; p<0.01 ; p<0.05 ; p<0.05$ соответственно); у курсантов женского пола - положительные с агрессией, гневом, враждебностью, макиавеллизмом, отрицательные - с «Согласием», «Добросовестностью» и пониманием собственных эмоций (уровень значимости корреляций $p<0.01 ; p<0.05 ; p<0.01$; $p<0.01 ; p<0.05 ; p<0.01$ соответственно); у курсантов мужского пола - положительные с агрессией, гневом, враждебностью, макиавеллизмом, отрицательные - с «Согласием» и «Добросовестностью» (уровень значимости корреляций $p<0.01 ; p<0.01 ; p<0.01 ; p<0.01 ; p<0.05 ; p<0.05$ соответственно); у студенток - положительные с агрессией, враждебностью, макиавеллизмом, отрицательные - с «Согласием», «Добросовестностью» и пониманием чужих эмоций (уровень значимости корреляций $p<0.01 ; p<0.05 ; p<0.01 ; p<0.01 ; p<0.05$; $p<0.05$ соответственно) (см. таблицу 3 ). Согласно результатам, выявляется следующая тенденция: во всех выборках АК отрицательно коррелирует с чертами «Большой пятерки», положительно с враждебностью и агрессией/макиавеллизмом (исключение составила выборка кадетов мужского пола).

Таблица 3

Значимые корреляции антисоциальной креативности с агрессией, чертами «Большой пятерки», макиавеллизмом и компонентами эмоционального интеллекта в выборках по полу и возрасту

\begin{tabular}{|l|c|c|c|c|c|}
\hline \multicolumn{1}{|c|}{ Параметры } & $\begin{array}{c}\text { Кадеты- } \\
\text { мужчины }\end{array}$ & $\begin{array}{c}\text { Кадеты- } \\
\text { женщины }\end{array}$ & $\begin{array}{c}\text { Курсанты- } \\
\text { женщины }\end{array}$ & $\begin{array}{c}\text { Курсанты- } \\
\text { мужчины }\end{array}$ & $\begin{array}{c}\text { Студенты- } \\
\text { женщины }\end{array}$ \\
\hline Агрессия & нет & $0.724^{* *}$ & $0.644^{* *}$ & $0.413^{* *}$ & $0.440^{* *}$ \\
\hline Гнев & $0.401^{* *}$ & нет & $0.380^{*}$ & $0.384^{* *}$ & нет \\
\hline Враждебность & $0.471^{* *}$ & $0.457^{* *}$ & $0.536^{* *}$ & $0.572^{* *}$ & $0.339^{*}$ \\
\hline Согласие & $-0.510^{* *}$ & $-0.559^{* *}$ & $-0.495^{* *}$ & $-0.187^{*}$ & $-0.544^{* *}$ \\
\hline Добросовестность & $-0.358^{* *}$ & $-0.558^{*}$ & $-0.552^{* *}$ & $-0.208^{*}$ & $-0.365^{*}$ \\
\hline Макиавеллизм & нет & $0.513^{*}$ & $0.362^{*}$ & $0.339^{* *}$ & $0.387^{* *}$ \\
\hline $\begin{array}{l}\text { Понимание своих } \\
\text { эмоций }\end{array}$ & нет & нет & $-0.487^{* *}$ & нет & нет \\
\hline $\begin{array}{l}\text { Понимание чужих } \\
\text { эмоций }\end{array}$ & нет & нет & нет & нет & $-0.337^{*}$ \\
\hline
\end{tabular}

${ }^{*} p<0.05,{ }^{* *} p<0.01$. 
Компоненты эмоционального интеллекта отрицательно коррелируют с антисоциальной креативностью только в женской выборке более старшего возраста (студентки и курсанты женского пола). Данный факт свидетельствует о важной роли в антисоциальной креативности таких параметров, как враждебность, «Согласие» и «Добросовестность».

Для проверки гипотез о половозрастной специфике предикторов АК (у мужчин - это враждебность, а у кадетов - черты «Большой пятерки») проводился множественный регрессионный анализ, при этом в качестве зависимой переменной рассматривалась антисоциальная креативность, в качестве независимых переменных - коррелирующие с АК показатели агрессии, черты «Большой пятерки», макиавеллизм, компоненты эмоционального интеллекта.

Было установлено, что 52\% дисперсии шкалы АК у кадетов мужского пола обусловлены влиянием враждебности и черты «Согласие» (стандартизованный коэффициент регрессии $\beta=0.466$ ( $p=0.004) ; \beta=-0.453(p=0.005)$ соответственно); 80\% дисперсии шкалы АК у кадетов женского пола обусловлены влиянием агрессии и черты «Добросовестность» $(\beta=0.589$ ( $p=0.000)$; $\beta=-0.434$ ( $p=0.004)$ соответственно); $53 \%$ дисперсии шкалы АК у курсантов женского пола обусловлено влиянием агрессии $(\beta=0.476$ ( $p=0.004) ; 34 \%$ дисперсии шкалы АК у курсантов мужского пола обусловлены влиянием враждебности и агрессии $(\beta=0.470(p=0.000) ; \beta=0.227(p=0.006)$ соответственно); $51 \%$ дисперсии шкалы АК у студенток обусловлен агрессией, чертой «Согласие» и пониманием собственных эмоций $(\beta=0.377$ ( $p=0.002)$; $\beta=-0.362(p=0.003) ; \beta=-0.349(p=0.003)$ соответственно). При этом агрессия вносит наибольший вклад в антисоциальную креативность у представительниц женского пола (у кадеток, курсанток и студенток коэффициент детерминации $R^{2}$ первого предиктора составил 67, 39 и 30\% соответственно), в то время как у выборок мужского пола - враждебность (у кадетов и курсантов $R^{2}$ первого предиктора составил 32 и $29 \%$ соответственно).

Относительно возрастной специфики антисоциальной креативности выявлено, что в отличие от взрослой части выборки (студенток и курсантов) вторым отрицательным предиктором антисоциальной креативности стали черты «Большой пятерки»: у кадетов женского пола - «Добросовестность», а у кадетов мужского пола - «Согласие». Такой закономерности у взрослой части выборки курсантов обоего пола выявлено не было. Все стандартизованные коэффициенты регрессии статистически достоверны (см. таблицу 4).

\section{Обсуждение результатов}

Согласно полученным результатам, выраженность антисоциальной креативности выше у подростков обоего пола по сравнению с женщинами и мужчинами старшего возраста, при этом никаких различий в уровне антисоциальной креативности между мужчинами и женщинами одного возраста выявлено не было. Сравнения по критерию Манна-Уитни показали, что выборки различаются по параметрам, вносящим вклад в дисперсию показателя антисоциальной креативности: в подростковом возрасте выше агрессия и враждебность 
Значимые корреляции антисоциальной креативности с агрессией, чертами «Большой пятерки», макиавеллизмом и компонентами эмоционального интеллекта в выборках по полу и возрасту

\begin{tabular}{|c|c|c|c|c|c|}
\hline Параметры & $\begin{array}{c}\text { Кадеты- } \\
\text { мужчины }\end{array}$ & $\begin{array}{c}\text { Кадеты- } \\
\text { женщины }\end{array}$ & $\begin{array}{l}\text { Курсанты- } \\
\text { женщины }\end{array}$ & $\begin{array}{l}\text { Курсанты- } \\
\text { мужчины }\end{array}$ & $\begin{array}{l}\text { Студенты- } \\
\text { женщины }\end{array}$ \\
\hline $\begin{array}{l}R^{2} / R^{2} \text { первого } \\
\text { предиктора, \% }\end{array}$ & $52 / 32$ & $80 / 67$ & 53 & $34 / 29$ & $51 / 30$ \\
\hline Агрессия & & $\begin{array}{l}1 . \beta=0589 \\
(p=0.000)\end{array}$ & $\begin{array}{c}1 . \beta=0.476 \\
(p=0.004)\end{array}$ & $\begin{array}{l}\text { 2. } \beta=0.227 \\
(p=0.006)\end{array}$ & $\begin{array}{l}1 . \beta=0377 \\
(p=0.002)\end{array}$ \\
\hline Враждебность & $\begin{array}{c}1 . \beta=0.466 \\
(p=0.004)\end{array}$ & & & $\begin{array}{c}1 . \beta=0.470 \\
(p=0.000)\end{array}$ & \\
\hline Согласие & $\begin{array}{c}\text { 2. } \beta=-0.453 \\
(p=0.005)\end{array}$ & & & & $\begin{array}{c}2 . \beta=-0.362 \\
(p=0.003)\end{array}$ \\
\hline Добросовестность & & $\begin{array}{c}2 . \beta=-0.434 \\
(p=0.004)\end{array}$ & & & \\
\hline $\begin{array}{l}\text { Понимание чужих } \\
\text { эмоций }\end{array}$ & & & & & $\begin{array}{c}3 . \beta=-0.349 \\
(p=0.003)\end{array}$ \\
\hline
\end{tabular}

и снижена черта «Согласие». Выявленная закономерность согласуется с результатами, полученными на выборке сотрудников полиции, имеющих юридическое образование, отличием которых от полицейских без высшего юридического образования стало отсутствие корреляций между АК и компонентами агрессии (Мешкова и др., 2018б). По-видимому, по мере взросления и получения специального образования (в нашем случае юридического) отрицательная выраженность данных показателей может снижаться.

Значимые предикторы антисоциальной креативности в зависимости от пола также различаются. Так, и у кадетов и курсантов мужского пола первым предиктором стала враждебность, в то время как у женщин (психологов, кадетов и курсантов) таким параметром стала агрессия. Полученные результаты не противоречат данным зарубежных исследователей под руководством М. Ранко (Hao et al., 2016), выявившим в качестве предиктора АК интегральный компонент агрессии, суммирующий значения по трем шкалам: «Агрессия», «Враждебность» и «Гнев». Полученные нами зависимости вносят уточнения и конкретизируют вклад компонентов агрессии в антисоциальную креативность с точки зрения половых особенностей респондентов, выявляя важность поведенческого компонента агрессии для женщин и когнитивного компонента агрессии - враждебности - для мужчин. Важно отметить, что в выборках курсантов не было выявлено значимых различий между мужчинами и женщинами, а в выборках кадетов выраженность враждебности обнаружена у девушек. При этом наблюдается выраженность агрессии у мужчин по сравнению с женщинами. Соответственно гипотеза о качественных особенностях предикторов антисоциальной креативности в выборках по полу получила свое подтверждение, причем враждебность свойственна мужчинам, а агрессия - женщинам. 
Что касается возрастных особенностей антисоциальной креативности, то здесь данные не столь однозначны. Так, в выборке мужчин были выявлены различия в предикторах АК: у кадетов отрицательным предиктором стала черта «Большой пятерки» - «Согласие», определяющая качество отношения человека к другим людям. Низкий уровень выраженности данной черты характеризует человека как мстительного, враждебного к другим, озабоченного своими потребностями, редко учитывающего интересы и нормы группы, действующего в соответствии с собственными принципами и склонного к манипулированию (McCrae, Costa, 1987). У курсантов предиктором стал поведенческий компонент, характеризующий в большей степени физическую агрессию. Таким образом, личностные особенности, ставшие предикторами, в обеих выборках имеют качественное отличие, что частично подтверждает вторую гипотезу.

Частичность подтверждения гипотезы определяется полученными результатами на женских выборках, в которых по возрастным признакам не было выявлено отличий между студентками и кадетами женского пола. В данных женских выборках отрицательным предиктором стали черты «Большой пятерки»: у студенток - «Согласие», а у кадетов женского пола - «Добросовестность», низкий уровень которой свидетельствует о низком уровне самоконтроля и гедонистической направленности индивида (Ibid.). В то же время в выборке курсантов женского пола единственным предиктором антисоциальной креативности стала агрессия, что подтверждает выдвинутую гипотезу. Неожиданное для нас выявление предиктора «Согласие» на выборке студенток нуждается в дальнейшем осмыслении. Объяснить полученные результаты можно с двух позиций. Во-первых, согласно результатам исследований, черта «Согласие» проявляется в девиантном поведении (García-Sancho et al., 2017). Также нами был показан вклад черт «Большой пятерки» в разные шкалы опросника АК: «Добросовестность» у подростков является одним из предикторов высоких показателей шкалы «Ложь», в то время как «Согласие» - шкал «Нанесение вреда» и «Злые шутки» (Бочкова, Мешкова, 2019). Таким образом, для уточнения результатов в дальнейшем следует провести пошкальный анализ предикторов у женщин разного возраста.

\section{Выводы}

Осуществленное исследование было посвящено выявлению возрастных и половых особенностей личностных предикторов антисоциальной креативности. Согласно полученным результатам, можно сделать следующие выводы:

1. Существуют возрастные особенности антисоциальной креативности, выявленные на группах кадетов и курсантов. У кадетов показатель АК выражен сильнее по сравнению с курсантами. Специфика подростковой антисоциально направленной креативности состоит в том, что в число ее отрицательных предикторов входят черты «Большой пятерки»: «Согласие» (у кадетов) и «Добросовестность» (у кадетов женского пола), что в выборке курсантов обоего пола выявлено не было. 
2. Существуют половые особенности в личностных предикторах антисоциальной креативности, выявленные на группах кадетов и курсантов обоего пола. Специфика женской антисоциальной креативности состоит в том, что первым предиктором в женской части выборок стала агрессия, а в мужской враждебность. Данный факт вносит уточнение в полученные ранее закономерности о вкладе компонентов агрессии в антисоциальную креативность.

Результаты проведенного исследования можно учитывать при разработке программ по профилактике и коррекции девиантного поведения у подростков. Направлением для дальнейшего исследования может стать изучение динамики феномена антисоциальной креативности на старшей возрастной выборке, а также исследование «беловоротничковой» преступности.

\section{Литература}

Бочкова, М. Н. (2020). Эмоциональный интеллект и креативность: связь и взаимодействие на примере разных категорий осужденных. Психология и право, 10(1), 90-100. doi:10.17759/ psylaw.2020100108

Бочкова, М. Н., Мешкова, Н. В. (2019). Поведенческие особенности негативной и антисоциальной креативности на примере подростков. Психолого-педагогические исследования, 11(1), 93106. doi:10.17759/psyedu.2019110108. Режим доступа: https://psyjournals.ru/files/98561/psyedu_2019_n1_Bochkova_Meshkova.pdf

Ениколопов, С. Н., Цибульский, Н. П. (2007). Психометрический анализ русскоязычной версии опросника диагностики агрессии А. Басса и М. Перри. Психологический журнал, 28(1), 115-124.

Знаков, В. В. (2000). Макиавеллизм: психологическое свойство личности и методика его исследования. Психологический журнал, 21(5), 16-22.

Люсин, Д. В. (2009). Опросник на эмоциональный интеллект ЭмИн: новые психометрические данные. В кн. Д. В. Люсин, Д. В. Ушаков (ред.), Социальный и эмоциональный интеллект. От процессов к измерениям (с. 187-200). М.: Институт психологии РАН.

Мешкова, Н. В. (2018). Особенности взаимосвязи антисоциально направленной креативности и ценностей у подростков с разным уровнем агрессии. Психолого-педагогические исследования, 10(2), 77-87 doi:10.17759/psyedu.2018100207. Режим доступа: https://psyjournals.ru/files/ 93998/psyedu_2018_n2_Meshkova.pdf

Мешкова, Н. В., Дебольский, М. Г., Ениколопов, С. Н., Масленков, А. А. (2018, а). Особенности креативности в социальном взаимодействии у осужденных, совершивших корыстные и агрессивно-насильственные преступления. Психология и право, 8(1), 147-163. doi:10.17759/psylaw.2018080111. Режим доступа: https://psyjournals.ru/files/91747/psyandlaw_2018_1_Meshkova_Debolsky_Enikolopov_et_al.pdf

Мешкова, Н. В., Ениколопов, С. Н. (2018). Креативность и девиантность: связь и взаимодействие. Психология. Журнал Высшей школь экономики, 15(2), 279-290. doi:10.17323/18138918-2018-2-279-290

Мешкова, Н. В., Ениколопов, С. Н., Митина, О. В., Мешков, И. А. (2018, б). Адаптация опросника «Поведенческие особенности антисоциальной креативности». Психологическая наука и образование, 23(6), 25-40. doi:10.17759/pse.2018230603. Режим доступа: https://psyjournals.ru/files/96688/pse_2018_n6_Meshkova_Enikolopov_et_al.pdf 
Мешкова, Н. В., Шаповал, В. А., Герасименко, Е. А., Потарыкина, М. С., Мешков И. А. (2018, в). Личностные особенности и антисоциальная креативность на примере кадетов и сотрудников МВД. Психология и право, 8(3), 83-96. doi:10.17759/psylaw.2018080306. Режим доступа: https://psyjournals.ru/files/95098/psyandlaw_2018_3_Meshkova_Shapoval_Gerasimenko.pdf Орел, В. Е., Сенгин, И. Г. (2004). Опросник NEO PI R. Ярославль: НПЦ «Психодиагностика».

Ссылки на зарубежные источники см. в разделе References после англоязычного блока.

Мешкова Наталья Владимировна - доцент, кафедра теоретических основ социальной психологии, факультет социальной психологии, ФГБОУ ВО «Московский государственный психолого-педагогический университет», кандидат психологических наук.

Сфера научных интересов: социальная психология, психология одаренности, психология креативности, юридическая психология.

Контакты: nmeshkova@yandex.ru

Ениколопов Сергей Николаевич - заведующий отделом медицинской психологии, Федеральное государственное бюджетное научное учреждение «Научный центр психического здоровья», кандидат психологических наук.

Сфера научных интересов: клиническая психология, юридическая психология, криминальная психология, психология юмора.

Контакты: enikolopov@mail.ru

Кудрявцев Владимир Товиевич - профессор, кафедра ЮНЕСКО «Культурно-историческая психология детства», ФГБОУ ВО «Московский государственный психолого-педагогический университет», доктор психологических наук.

Сфера научных интересов: креативность, воображение.

Контакты: vtkud@mail.ru

Кравцов Олег Геннадьевич - доцент, кафедра юридической психологии, УНК ПСД Московского университета МВД России им. В.Я. Кикотя, кандидат психологических наук, доцент.

Сфера научных интересов: девиантное поведение, юридическая психология.

Контакты: kravtsovog@gmail.com

Бочкова Маргарита Николаевна - магистр.

Сфера научных интересов: социальная психология, психология креативности, юридическая психология.

Контакты: Boschkova.m84@gmail.com

Мешков Иван Андреевич - магистр.

Сфера научных интересов: социальная психология, психология креативности, юридическая психология.

Контакты: ivan_meshkov1985@mail.ru 


\title{
Age and Gender Characteristics of Personality Predictors for Antisocial Creativity
}

\author{
N.V. Meshkova ${ }^{a}$, S.N. Enikolopov ${ }^{b}$, V.T. Kudryavtseva ${ }^{a}$ O.G. Kravtsov', \\ M.N. Bochkova, I.A. Meshkov
}

\begin{abstract}
${ }^{a}$ Moscow State University of Psychology and Education, 29 Sretenka Str., Moscow, 127051, Russian Federation

${ }^{b}$ The Mental Health Research Center, 34 Kashirskoe Highway, Moscow, 115522, Russian Federation

${ }^{c}$ V.Ya. Kikot' Moscow University of the Ministry of Internal Affairs of the Russian Federation, Russian Federation
\end{abstract}

\begin{abstract}
Malevolent creativity (MC) is manifested in the implementation of one's own or somebody else's original ideas that harm other people. Analysis of previous studies shows that there are age and gender specifics. We present the results of a study of MC predictors, taking into account age and gender of the respondents. The sample $(\mathrm{N}=293)$ : men $(\mathrm{N}=192)$; cadets $(\mathrm{N}=97)$, cadets of high school $(\mathrm{N}=150)$ and students of high school $(\mathrm{N}=46$, women $)$. A battery of questionnaires was used to measure aggression, MAK-IV, emotional intelligence, personality traits of the Big Five, behavioral characteristics of MC. Qualitative gender characteristics of MC predictors were revealed: in men, this is hostility, and in women, aggression. According to the results of the regression analysis, the specificity of adolescent $\mathrm{MC}$ is that negative predictors include Consciousness and Agreeableness traits associated with deviant behavior, but not in adult respondents. The results obtained can be used to develop programs for the prevention of deviant behavior in adolescents.
\end{abstract}

Keywords: malevolent creativity, cadets, Big Five, hostility, aggression.

\section{References}

Bochkova, V. N. (2020). Emotional intelligence and creativity: Interrelation and interaction in different categories of convicts. Psikhologiia i Pravo [Psychology and Law], 10(1), 90-100. doi:10.17759/ psylaw.2020100108. (in Russian)

Bochkova, V. N., \& Meshkova, N. V. (2019). Behavioral features of negative and malevolent creativity in adolescents. Psychological-Educational Studies, 11(1), 93-106. doi:10.17759/psyedu.2019110108. Retrieved from https://psyjournals.ru/files/98561/psyedu_2019_n1_Bochkova_Meshkova.pdf (in Russian)

Enikolopov, S. N., \& Tsibul'sky, N. P. (2007). Psychometric analysis of Russian-language version of questionnaire for aggression diagnostics by A. Bass and M. Perry. Psikhologicheskii Zhurnal, 28(1), 115-124. (in Russian)

This work was carried out with financial support from the Russian Foundation for Basic Research, research project N 19-013-00240-A. 
García-Sancho, E., Salguero, J. M., \& Fernández-Berrocal, P. (2017). Ability emotional intelligence and its relation to aggression across time and age groups. Scandinavian Journal of Psychology, 58(1), 43-51. doi:10.1111/sjop.12331

Hao, N., Tang, M., Yang, J., Wang, Q., \& Runco, M. A. (2016). A new tool to measure malevolent creativity: The Malevolent Creativity Behavior Scale. Frontiers in Psychology, 7, 682. doi:10.3389/fpsyg.2016.00682

Lyusin, D. V. (2009). Oprosnik na emotsional'nyi intellekt EmIn: novye psikhometricheskie dannye [Questionnaire EmIn's on emotional intelligence: new psychometric data]. In D. V. Lyusin \& D. V. Ushakov (Eds.), Sotsial'nyi i emotsional'nyi intellekt. Ot protsessov k izmereniyam [Social and emotional intelligence. From processes to measurements] (pp. 187-200). Moscow: Institute of Psychology of the RAS. (in Russian)

McCrae, R. R., \& Costa, P. T. (1987). Validation of the five - factor model of personality across instruments and observers. Journal of Personality and Social Psychology, 52, 81-90.

Meshkova, N. V. (2018). Interrelation of malevolent creativity and values in adolescents with different levels of aggression. Psikhologo-pedagogicheskie Issledovaniya [Psychological-Educational Studies], 10(2), 77-87. doi:10.17759/psyedu.2018100207. Retrieved from https://psyjournals.ru/ files/93998/psyedu_2018_n2_Meshkova.pdf (in Russian)

Meshkova, N. V., Debolsky, M. G., Enikolopov, S. N., \& Maslenkov, A. A. (2018, a). Features of creativity in social interaction among convicts who have committed self-serving and aggressively violent crimes. Psikhologiia $i$ Pravo [Psychology and Law], 8(1), 147-163. doi:10.17759/psylaw.2018080111. Retrieved from https://psyjournals.ru/files/91747/psyandlaw_2018_1_Meshkova_Debolsky_Enikolopov_et_al.pdf (in Russian)

Meshkova, N. V., \& Enikolopov, S. N. (2018). Creativity and deviance: Communication and interaction. Psychology. Journal of High School of Economy, 15(2), 279-290. doi:10.17323/1813-89182018-2-279-290 (in Russian)

Meshkova, N. V., Enikolopov, S. N., Mitina, O. V., \& Meshkov, I. A. (2018, b). Adaptation of the Malevolent Creativity Behavior Scale. Psikhologicheskaya Nauka i Obrazovanie [Psychological Science and Education], 23(6), 25-40. doi:10.17759/pse.2018230603. Retrieved from https://psyjournals.ru/files/96688/pse_2018_n6_Meshkova_Enikolopov_et_al.pdf (in Russian)

Meshkova, N. V., Shapoval, V. A., Gerasimenko, E. A., Potarykina, M., \& Meshkov, I. A. (2018, c). Personal features and malevolent creativity on the example of cadets and policemen. Psikhologiia i Pravo [Psychology and Law], 8(3), 83-96. doi:10.17759/psylaw.2018080306. https://psyjournals.ru/files/95098/psyandlaw_2018_3_Meshkova_Shapoval_Gerasimenko.pdf (in Russian)

Natalya V. Meshkova - Associate Professor, Chair of Theoretical Foundations of Social Psychology, Moscow State University of Psychology \& Education, Ph.D.

Research Area: social psychology, psychology of giftedness, psychology of creativity, forensic psychology.

E-mail: nmeshkova@yandex.ru

Sergei N. Enikolopov - Head of the Department of Medical Psychology, Mental Health Research Center, Ph.D.

Research Area: clinical psychology, forensic psychology, victimology, psychology of humor.

E-mail: enikolopov@mail.ru 
Vladimir T. Kudryavtsev - Professor, Moscow State University of Psychology \& Education, DSc.

Research Area: creativity, imagination.

E-mail: vtkud@mail.ru

Oleg G. Kravtsov - Associate Professor, Juristic Psychology Department, V.Ya. Kikot' Moscow University of the Ministry of Internal Affairs of the Russian Federation, PhD.

Research Area: deviant behavior, forensic psychology.

E-mail: kravtsovog@gmail.com

Margarita N. Bochkova - MSc.

Research Area: social psychology, psychology of creativity, forensic psychology.

E-mail: Boschkova.m84@gmail.com

Ivan A. Meshkov - MSc.

Research Area: social psychology, psychology of creativity, forensic psychology.

E-mail: ivan_meshkov1985@mail.ru 